\title{
PREPARASI MAGNETIT PASIR BESI TERDISPERSI NATRIUM SITRAT UNTUK ADSORPSI Au(III)
}

\author{
Ricka Prasdiantika \\ Fakultas Teknik Universitas Pandanaran \\ Jl. Banjarsari Barat No. 1 Semarang \\ Email: ricka.prasdiantika@upand.ac.id \\ Susanto \\ Fakultas Teknik Universitas Pandanaran \\ Jl. Banjarsari Barat No. 1 Semarang
}

\begin{abstract}
This study aims to the preparation material magnetite $\left(\mathrm{Fe}_{3} \mathrm{O}_{4}\right)$ of iron sand dispersed sodium citrate ( $\mathrm{Fe}_{3} \mathrm{O}_{4} @$ @itrate), and its application to adsorption of metal ions Au(III). Preparation was done by was separating the magnetic material of iron sand using an external magnet and washed with $\mathrm{H}_{2} \mathrm{O}$. Magnetite was soaked with sodium citrate solution $0.5 \mathrm{M}$ as the dispersion medium. Materials were characterized by Fourier Transform Infrared (FT-IR) Spectrophotometer, and Transmission Electron Microscope (TEM). Adsorption ability of the material to $\mathrm{Au}(\mathrm{III})$ was evaluated in $\mathrm{HAuCl}_{4}$ solution with a concentration of $\mathrm{Au}(\mathrm{III}) 200 \mathrm{ppm}$ and $\mathrm{pH} 3$ for 120 minutes. Concentration of $\mathrm{Au}(\mathrm{III})$ which was not adsorbed was analyzed with Atomic Absorption Spectroscopy (AAS). The characterization results indicate that $\mathrm{Fe}_{3} \mathrm{O}_{4} @$ citrate successfully prepared by having a better particle dispersion and aggregate less than $\mathrm{Fe}_{3} \mathrm{O}_{4}$ iron sand without citrate. Material $\mathrm{Fe}_{3} \mathrm{O}_{4} @$ citrate tested the ability of metal ion adsorption on $\mathrm{Au}(\mathrm{III})$ at $200 \mathrm{ppm} \mathrm{HAuCl}_{4}$ solution with a pH of 3. Material $\mathrm{Fe}_{3} \mathrm{O}_{4} @$ citrate which was able to adsorb metal ions $\mathrm{Au}(\mathrm{III})$ with the amount of $83.667 \pm 0.727 \mathrm{mg} / \mathrm{g}$.
\end{abstract}

Keywords: Magnetite Iron Sand, Particle Dispersion, Solution Sodium Citrate, Adsorption Au (III)

\begin{abstract}
ABSTRAK
Penelitian ini bertujuan untuk mempreparasi material magnetit $\left(\mathrm{Fe}_{3} \mathrm{O}_{4}\right)$ dari pasir besi yang terdispersi natrium sitrat $\left(\mathrm{Fe}_{3} \mathrm{O}_{4} @\right.$ sitrat), dan aplikasinya untuk adsorpsi ion logam $\mathrm{Au}(\mathrm{III})$. Preparasi dilakukan dengan memisahkan bahan magnetik dari pasir besi dengan menggunakan magnet eksternal dan dicuci dengan $\mathrm{H}_{2} \mathrm{O}$. Material yang diperoleh direndam dengan larutan natrium sitrat $0,5 \mathrm{M}$ sebagai media pendispersi. Material dikarakterisasi dengan Spectrophotometer Fourier Transform Infrared (FTIR), dan Transmission Electron Microscope (TEM). Kemampuan adsorpsi material terhadap Au(III) dilakukan pada larutan $\mathrm{HAuCl}_{4}$ dengan konsentrasi $\mathrm{Au}$ (III) 200 ppm dan pH 3 selama 120 menit. Kadar $\mathrm{Au}(\mathrm{III})$ yang tidak teradsorpsi dianalisis dengan Atomic Absorption Spectroscopy (AAS). Hasil karakterisasi mengindikasikan bahwa $\mathrm{Fe}_{3} \mathrm{O}_{4} @$ sitrat berhasil dipreparasi dengan dispersi partikel yang lebih baik dan agregat yang lebih sedikit dibandingkan $\mathrm{Fe}_{3} \mathrm{O}_{4}$ pasir besi tanpa sitrat. Material $\mathrm{Fe}_{3} \mathrm{O}_{4} @$ sitrat mampu mengadsorpsi ion logam Au(III) sebanyak 83,667士 0,727 mg/g.
\end{abstract}

Kata kunci: Magnetit Pasir Besi, Dispersi Partikel, Larutan Natrium Sitrat, Adsorpsi Au(III) 


\section{PENDAHULUAN}

Emas saat ini tidak hanya digunakan sebagai bahan untuk membuat perhiasan saja, tetapi juga banyak digunakan dalam berbagai bidang seperti industri elektronik (Kim dkk., 2011), industri kimia (Corti dkk., 2007), dan bidang kesehatan (Mukherjee dkk., 2007). Emas di alam tidak ditemukan sebagai material tunggal, keberadaanya selalu bersamaan dengan logamlogam lain. Emas terkandung dalam mineralmineral seperti kalkopirit, pirhotit, pirit, dan arsenopirit (Sahoo dan Venkatesh, 2015). Oleh karena itu, diperlukan metode untuk memisahkan emas dari campuran logam-logamnya.

Metode umum yang sering digunakan untuk pemisahan emas adalah metode sianida dan metode amalgamasi karena murah dan sederhana (Watling, 2007), namun kedua metode tersebut memiliki kelemahan. Metode sianida menggunakan prekursor natrium sianida yang sangat beracun dan prosesnya berjalan sangat lambat, sedangkan metode amalgamasi menggunakan prekursor merkuri yang berdampak pada pencemaran lingkungan. Oleh karena itu, diperlukan metode lain yang lebih efektif, efisien, dan aman bagi lingkungan untuk memisahkan emas.

Salah satu metode alternatif yang dapat digunakan adalah metode adsorpsi. Metode adsorpsi merupakan metode yang ramah lingkungan, tidak menggunakan banyak pelarut, tidak menghasilkan limbah berbahaya (Qu dkk., 2009), murah, dapat diaplikasikan pada konsentrasi ion logam yang rendah (Kraus dkk., 2009), dan dapat digunakan berulang (Chung dkk., 2012).

Adsorpsi dapat dilakukan dengan berbagai macam adsorben seperti biosorben bakteri dan ragi (Tsuruta, 2004), ganggang (Umali dkk., 2006), dan biomassa alga hijau Spirogyra sp (Gupta dkk., 2008). Namun, biosorben tersebut memiliki kelemahan seperti ukurannya yang kecil, berat jenis yang rendah, strukturnya yang mudah rusak karena terdekomposisi oleh mikroorganisme lain, sulit digunakan dalam kolom (Buhani dkk., 2006), dan mudah mengalami lisis pada kondisi asam.

Alternatif adsorben yang dapat digunakan adalah material magnetik seperti magnetit. Magnetit dapat digunakan untuk mengadsorpsi ion-ion logam berat seperti ion logam $\mathrm{Hg}$ (II) (Pan dkk., 2012), Cd(II), dan Cr (IV) (Silva-silva dkk., 2016). Magnetit biasanya disintesis menggunakan prekursor garam $\mathrm{FeCl}_{3} \cdot 6 \mathrm{H}_{2} \mathrm{O}$ dan $\mathrm{FeCl}_{2} \cdot 4 \mathrm{H}_{2} \mathrm{O}$ (Zhang dkk., 2013), $\mathrm{FeSO}_{4} .7 \mathrm{H}_{2} \mathrm{O}$ (Iida dkk., 2007), atau $\mathrm{Fe}\left(\mathrm{NO}_{3}\right)_{3} .9 \mathrm{H}_{2} \mathrm{O}$ (Chung dkk., 2012). Namun, prekursor tersebut relatif mahal dan menghasilkan limbah baru. Oleh karena itu, diperlukan sumber magnetit yang lebih efektif, efisien, dan aman bagi lingkungan untuk mengganti prekursor tersebut. Sumber magnetit tersebut dapat diganti dengan magnetit yang berasal dari pasir besi alam.

Pasir besi alam pada umumnya mempunyai komposisi utama oksida besi yaitu magnetit $\left(\mathrm{Fe}_{3} \mathrm{O}_{4}\right)$, hematit $\left(\alpha-\mathrm{Fe}_{2} \mathrm{O}_{3}\right)$, dan maghemit $\left(\gamma-\mathrm{Fe}_{2} \mathrm{O}_{3}\right)$ (Cornell dan Schwertmann, 2003), beberapa senyawa oksida lain seperti $\mathrm{Al}_{2} \mathrm{O}_{3}, \mathrm{MgO}$, dan $\mathrm{SiO}_{2}$ (Komatina dkk., 2004).

Magnetit memiliki sifat mudah teroksidasi (Farimani dkk., 2013), tidak stabil dalam kondisi asam (Zhang dkk., 2013), dan mudah mengalami agregasi (Yantasee dkk., 2007). Oleh karena itu, diperlukan cara agar partikel magnetit tidak membentuk agregat. Lu dkk. (2007) melakukan penambahan asam oleat pada tahap sintesis coating material magnetit untuk mengontrol dispersi dan ukuran material magnetit. Namun, penggunaan asam oleat tidak efektif, karena kemampuannya dalam mengontrol dispersi dan ukuran materialnya tidak stabil.

Yang dkk. (2009) melakukan kontrol (ukuran material, homogenitas material, dan proses dispersi) dalam sintesis nanokomposit magnetitsilika dengan menggunakan stabilizer (natrium sitrat) melalui proses pembentukan kompleks dengan metode sol-gel. Hasil sintesis menunjukkan bahwa penggunaan natrium sitrat dapat mengontrol ukuran, dispersi dan homogenitas magnetit nanokomposit. Oleh karena itu, pada penelitian ini digunakan agen pendispersi natrium sitrat untuk meningkatkan stabilitas dispersi partikel, dan meminimalisir terbentuknya agregat.

Dalam penelitian ini dilakukan preparasi magnetit dari pasir besi yang terdispersi natrium sitrat, dan pengujian kemampuan adsorpsi magnetit pasir besi terdispersi natrium sitrat $\left(\mathrm{Fe}_{3} \mathrm{O}_{4} @\right.$ sitrat $)$ terhadap ion logam $\mathrm{Au}(\mathrm{III})$ pada larutan $\mathrm{HAuCl}_{4}$. Penelitian ini dapat memberikan alternatif penggunaan pasir besi sebagai sumber magnetit untuk adsorpsi ion logam $\mathrm{Au}(\mathrm{III})$.

\section{METODE PERCOBAAN}

\section{Bahan dan Alat}

Bahan-bahan yang digunakan untuk preparasi material magnetit pasir besi yaitu pasir besi alam yang berasal dari pesisir pantai Desa Lansilowo Kecamatan Wawonii Utara Kabupaten 
Konawe Kepulauan Propinsi Sulawesi Tenggara, akuades, dan natrium sitrat $0,5 \mathrm{M}$ (Merck).

Peralatan yang digunakan meliputi peralatan preparasi dan peralatan analisis. Peralatan preparasi terdiri dari labu ukur berbagai ukuran, gelas ukur berbagai ukuran, gelas Beaker berbagai ukuran, labu Erlenmeyer berbagai ukuran, lumpang, mortar porselen, Shaker VRN 200 (130 rpm), oven (Fisher Scientific), neraca analitik (Mettler AE 160), sonikator (bransonik 3210 dengan frekuensi $48 \mathrm{KHz} ; 220$ volt) dan magnet eksternal (Niobium).

Peralatan analisis yang digunakan dalam penelitian ini yaitu Fourier Transform Infrared Spectrophotometer (FT-IR) Shimadzu FTIRPRESTIGE 21 untuk identifikasi gugus fungsional material, Transmission Electron microscopy (TEM) JEOL JEM-1400 untuk mengamati morfologi dan dispersi material, dan Atomic Absorption Spectroscopy (AAS) Analytic Jena contrAA 300 untuk menganalisis dan menghitung konsentrasi Au total yang teradsorpsi.

\section{Cara Kerja}

Preparasi magnetit pasir besi terdispersi natrium sitrat. Material magnetik dari pasir besi dipisahkan dengan menggunakan magnet eksternal. Padatan yang tertarik oleh magnet eksternal dikeringkan pada oven dengan temperatur $80^{\circ} \mathrm{C}$ selama 24 jam. Material magnetik pasir besi hasil preparasi dimasukkan ke dalam gelas kimia sebanyak 5 gram. Kemudian dicuci dengan akuades dan disonikasi selama 30 menit sebanyak 3 kali. Campuran yang diperoleh pada gelas kimia dipisahkan dengan magnet eksternal dan diambil endapannya. Selanjutnya material magnetik direndam dalam $100 \mathrm{~mL}$ larutan natrium sitrat $0,5 \mathrm{M}$. Endapan yang diperoleh dikeringkan pada temperatur $80^{\circ} \mathrm{C}$ selama 24 jam, digerus dan ditimbang. Serbuk material yang diperoleh dikarakterisasi dengan spektrofotometer FT-IR, dan TEM.

Adsorpsi $\quad \mathbf{A u}(\mathbf{I I I})$. Sebanyak $10 \mathrm{mg}$ material hasil preparasi ditempatkan dalam botol plastik. Adsorpsi dilakukan dalam sistem batch dengan menambahkan $10 \mathrm{ml}$ larutan $\mathrm{HAuCl}_{4}$ dengan konsentrasi $\mathrm{Au}(\mathrm{III}) 200 \mathrm{ppm}$ dan pH $3 \mathrm{ke}$ dalam botol plastik yang berisi material. Campuran material dan larutan $\mathrm{Au}(\mathrm{III})$ digojog dengan shaker selama 120 menit. Material dan supernatan dipisahkan menggunakan magnet eksternal. Supernatan dianalisis dengan AAS untuk menentukan konsentrasi $\mathrm{Au}(\mathrm{III})$ yang tidak teradsorpsi.

\section{HASIL DAN PEMBAHASAN}

Preparasi. Sampel pasir besi diperoleh dari pesisir pantai Desa Lansilowo Kecamatan Wawonii Utara Kabupaten Konawe Kepulauan Propinsi Sulawesi Tenggara. Pasir besi dipisahkan dengan menggunakan magnet eksternal untuk memisahkan material magnetik dari pengotorpengotornya yang tidak dapat tertarik oleh magnet. Material magnetik dicuci dengan $\mathrm{H}_{2} \mathrm{O}$ untuk menghilangkan pengotor-pengotor yang dapat larut dengan $\mathrm{H}_{2} \mathrm{O}$. Material magnetik yang diperoleh dari pasir besi Lansilowo didominasi oleh magnetit (Prasdiantika, 2015).

Material magnetik hasil preparasi dikarakterisasi dengan spektofotometer FT-IR dan TEM untuk mengetahui gugus fungsional yang ada dalam material dan mengidentifikasi terbentuknya magnetit pasir besi dan magnetit pasir besi terdispersi natrium sitrat. Hasil karakterisasi spektrofotometer FT-IR magnetit pasir besi dan magnetit pasir besi terdispersi sitrat ditunjukkan pada Gambar 1.

Berdasarkan Gambar 1, teridentifikasi beberapa pita serapan dari hasil preparasi material, diantaranya terdapat pita serapan pada bilangan gelombang $1636 \mathrm{~cm}^{-1}$ yang mengindikasikan vibrasi tekuk dari gugus hidroksida $(\mathrm{O}-\mathrm{H})$ pada permukaan oksida besi $(\mathrm{Fe}-\mathrm{OH})$ dan air $\left(\mathrm{H}_{2} \mathrm{O}\right)$ (Farimani dkk., 2013). Pada bilangan gelombang $3426 \mathrm{~cm}^{-1}$ mengindikasikan adanya vibrasi ulur $\mathrm{OH}$ dari $\mathrm{Fe}-\mathrm{OH}$ pada permukaan magnetit yang berinteraksi dengan air (Petcharoen dkk., 2012). Bilangan gelombang pada $2855 \mathrm{~cm}^{-1}$ dan $2916 \mathrm{~cm}^{-}$ 1 mengindikasikan adanya vibrasi ulur simetris dan asimetris C-H (Jacintho dkk., 2009).

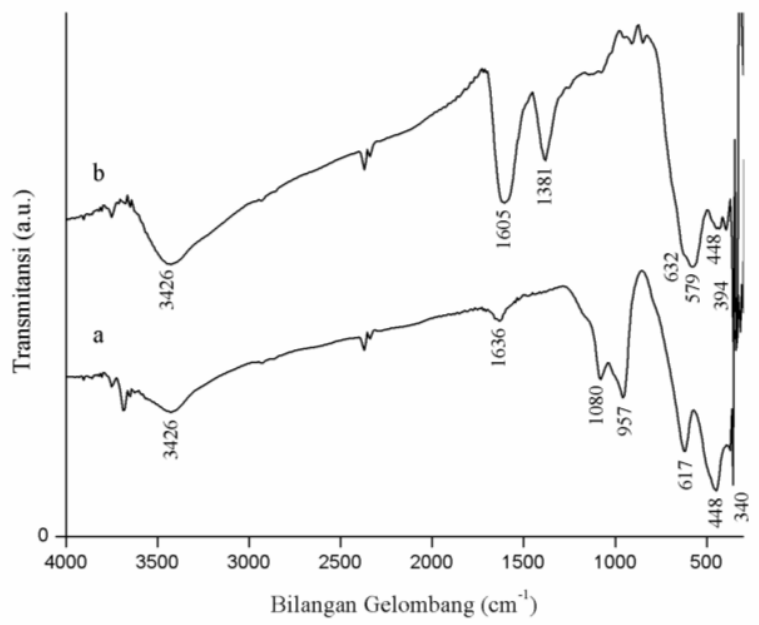

Gambar 1. Spektra FT-IR (a) magnetit pasir besi dan (b) magnetit pasir besi terdispersi sitrat 
Berdasarkan pada Gambar 1, munculnya bilangan gelombang 448, 579, dan $617 \mathrm{~cm}^{-1}$ mengindikasikan adanya vibrasi ulur $\mathrm{Fe}-\mathrm{O}$ (Jitianu dkk., 2006, Yamaura dkk., 2004). Vibrasi ulur tersebut mengindikasikan vibrasi ulur $\mathrm{Fe}-\mathrm{O}$ dari magnetit. Hal ini menunjukkan bahwa material magnetik pasir besi yang dipreparasi mengandung oksida besi magnetit. Hal ini didukung oleh analisis spektra FT-IR dari magnetit yang dicirikan oleh pita serapan yang lebar disekitar bilangan gelombang $636 \mathrm{~cm}^{-1}$ seperti yang dikemukakan oleh Lakay (2009), dan bilangan gelombang kurang dari $700 \mathrm{~cm}^{-1}$ yang menunjukkan vibrasi ikatan $\mathrm{Fe}-\mathrm{O}$ dari $\mathrm{Fe}_{3} \mathrm{O}_{4}$ seperti yang dikemukakan oleh Montagne dkk. (2002).

Preparasi material magnetit dengan capping agent natrium sitrat yang terikat pada permukaannya dapat dijelaskan melalui pembentukan ikatan antara $\mathrm{Fe}$ dengan gugus $\mathrm{COO}^{-}$ yang teridentifikasi pada bilangan gelombang $\sim 1400 \mathrm{~cm}^{-1}$, dan $\sim 1600 \mathrm{~cm}^{-1}$. Pada bilangan gelombang $1381 \mathrm{~cm}^{-1}$ menunjukkan adanya gugus vibrasi ulur simetri $\mathrm{COO}^{-}$dari gugus sitrat (Farimani dkk., 2013). Bilangan gelombang $1605 \mathrm{~cm}^{-1}$ menunjukkan vibrasi ulur asimetri $\mathrm{COO}^{-}$ dari sitrat yang tumpang tindih vibrasi ulur $\mathrm{OH}$ dari gugus sitrat serta permukaan magnetit yang berinteraksi dengan air (Farimani dkk., 2013). Pada bilangan gelombang pada $632 \mathrm{~cm}^{-1}$ mengindikasikan adanya interaksi $\mathrm{Fe}$ dengan $\mathrm{COO}^{-}$ sitrat (Hong dkk., 2008). Pada bilangan gelombang $3426 \mathrm{~cm}^{-1}$ mengindikasikan adanya vibrasi ulur-OH dari gugus sitrat (Farimani dkk., 2013).

Selisih antara vibrasi asimetri $\left(\mathrm{COO}^{-}\right)$dan vibrasi simetri $\left(\mathrm{COO}^{-}\right)(\Delta)$ dapat digunakan untuk menjelaskan tipe interaksi antara kepala karboksilat dengan atom logam. Harga $\Delta$ antara 200-320 $\mathrm{cm}^{-1}$ maka dimungkinkan interaksi yang terjadi adalah interaksi monodentat, apabila harga $\Delta$ kurang dari $100 \mathrm{~cm}^{-1}$ merupakan interaksi khelating bidentat dan pada rentang $150-200 \mathrm{~cm}^{-1}$ merupakan interaksi jembatan bidentat seperti yang dikemukakan oleh Jacintho dkk. (2009).

Berdasarkan data FT-IR pada Gambar 1 dapat ditentukan selisih antara vibrasi asimetri ($\left.\mathrm{COO}^{-}\right)$dengan vibrasi simetri $\left(-\mathrm{COO}^{-}\right)$yaitu sebesar $224 \mathrm{~cm}^{-1}$ yang berarti menunjukkan adanya interaksi jembatan monodentat antara kepala karboksilat dengan atom $\mathrm{Fe}$ secara kovalen pada posisi oktahedral.

Berdasarkan karakterisasi dengan menggunakan spektofotometer FT-IR, terdapat puncak-puncak bilangan gelombang karakteristik, terbentuknya puncak-puncak spektra inframerah yang karakteristik dari magnetit dan adanya gugus fungsi $-\mathrm{OH}$ dan gugus $-\mathrm{COO}^{-}$dari sitrat serta ikatan $\mathrm{Fe}-\mathrm{O}$ dan interaksi antara $\mathrm{Fe}$ dari magnetit dengan $-\mathrm{COO}^{-}$dari sitrat. Hal ini menunjukkan bahwa magnetit tanpa sitrat dan magnetit terdispersi sitrat telah berhasil dipreparasi.

Magnetit pasir besi dan magnetit pasir besi@sitrat hasil preparasi kemudian dikarakterisasi dengan TEM untuk mengetahui dispersi partikelnya. Hasil karakterisasi TEM magnetit pasir besi dan magnetit pasir besi@sitrat hasil preparasi ditunjukkan pada Gambar 2.

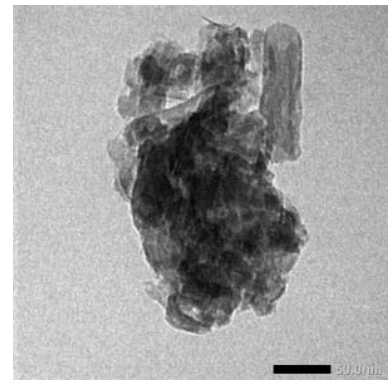

(a)

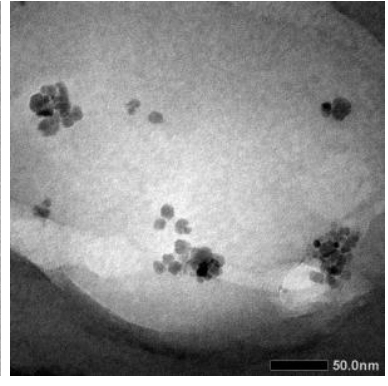

(b)
Gambar 2. Citra TEM dari (a) magnetit pasir besi, (b) magnetit pasir besi@ sitrat

Berdasarkan citra material magnetit pasir besi menggunakan TEM terlihat bahwa penggunaan natrium sitrat dapat mengontrol dispersi partikel material magnetit. Gambar 2 (a) merupakan hasil citra TEM material magnetit pasir besi sebelum direndam dengan natrium sitrat. Pada gambar tersebut terlihat adanya penumpukan partikel magnetit yang membentuk agregat. Gambar 2 (b) adalah citra material magnetit yang sudah direndam dengan natrium sitrat. Pada gambar tersebut terlihat adanya bulatan-bulatan partikel magnetit yang berwarna cerah yang menunjukkan bahwa tidak terjadi penumpukan dari partikel magnetit.

Berdasarkan hasil TEM pada Gambar 2, $\mathrm{Fe}_{3} \mathrm{O}_{4} @$ sitrat memiliki dispersi yang lebih baik dibandingkan $\mathrm{Fe}_{3} \mathrm{O}_{4}$ tanpa sitrat. $\mathrm{Hal}$ ini mengindikasikan bahwa natrium sitrat berhasil mengontrol dispersi partikel magnetit. Pada gambar tersebut juga terlihat bahwa partikel magnetit yang direndam menggunakan natrium sitrat memiliki ukuran yang lebih kecil apabila dibandingkan dengan partikel magnetit yang tidak direndam dengan larutan natrium sitrat. Hal ini dimungkinkan karena gugus sitrat bermuatan negatif sehingga menyebabkan tolakan antar gugus 
sitrat dan menghasilkan jarak antara satu dengan yang lain (Yang dkk., 2009).

Sitrat dapat membentuk kompleks dengan Fe pada partikel magnetit. Adanya gugus $-\mathrm{COO}^{-}$ dari sitrat memungkinkan terbentuknya muatan negatif disekeliling partikel magnetit yang menyelubungi partikel material magnetik. Muatan negatif tersebut akan menimbulkan gaya tolakmenolak antar partikel magnetit, sehingga pembentukan agregat dari partikel bahan magnetit dapat dicegah dan menghasilkan partikel dengan dispersi yang lebih baik seperti yang dikemukakan Kazemi dkk. (2013). Tolakan elektrostatik yang terjadi dapat meningkatkan stabilitas dispersi dari partikel seperti yang dikemukakan oleh Yang dkk. (2009).

Partikel magnetit rentan mengalami agregasi (Lu dkk., 2002) baik dalam kondisi padatan kering maupun dalam larutannya. Agregasi disebabkan karena kuatnya tarikan dipolar antar partikel magnetik itu sendiri. Oleh karena itu, partikel magnetit perlu direndam dengan larutan natrium sitrat $0,5 \mathrm{M}$ sebagai media pendispersi selama 24 jam. Hal ini bertujuan agar partikel magnetit tidak saling bertumpuk satu sama lain membentuk agregat dan diperoleh partikel magnetit dengan dispersi yang baik.

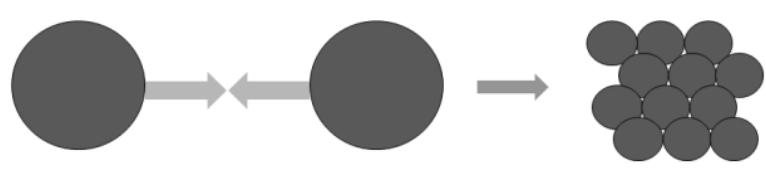

Gambar 3. Ilustrasi pembentukan agregat akibat gaya tarik antar partikel magnetit

Penggunaan natrium sitrat cukup efektif untuk mencegah terjadinya agregasi partikel magnetit yang terbentuk yang dapat dilihat dari karakterisasi menggunakan TEM yang ditunjukkan pada Gambar 2. Sebelum dilakukan perendaman dengan natrium sitrat, secara visual serbuk partikel magnetit terlihat menggumpal dan sulit terlihat butirannya ketika diuji dengan magnet eksternal. Setelah dilakukan perendaman dengan natrium sitrat, serbuk partikel magnetit secara visual dapat terlihat butiran-butirannya.

Berdasarkan hasil karakterisasi TEM, dan spektofotometer FT-IR menunjukkan bahwa magnetit pasir besi terdispersi natrium sitrat berhasil dipreparasi.

Adsorpsi. Adsorpsi $\mathrm{Au}(\mathrm{III})$ oleh magnetit pasir besi@sitrat dilakukan menggunakan larutan $\mathrm{HAuCl}_{4}$ pada konsentrasi $\mathrm{Au}(\mathrm{III}) 200 \mathrm{ppm}$ dan $\mathrm{pH}$ 3 selama 120 menit. Kondisi tersebut merupakan kondisi optimum untuk adsorpsi Au(III) seperti yang dilakukan oleh Syukur (2014). Pada pH 3, spesi $\mathrm{Au}(\mathrm{III})$ berada pada kondisi $\left[\mathrm{AuCl}_{4}\right]^{-}$dengan fraksi mol optimum sebagaimana dikemukakan oleh Paclawski dan Fitzner (2004).

Berdasarkan hasil analisis menggunakan AAS, magnetit pasir besi@sitrat mampu mengadsorpsi ion logam $\mathrm{Au}(\mathrm{III})$ dalam bentuk

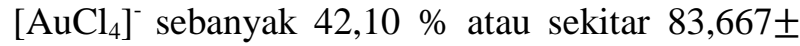
$0,727 \mathrm{mg} / \mathrm{g}$. Proses adsorpsi yang dilakukan dalam penelitian ini, bertujuan untuk membuktikan material magnetit pasir besi@sitrat yang dipreparasi mampu mengadsorpsi ion logam $\mathrm{Au}(\mathrm{III})$. Magnetit pasir besi@sitrat yang telah dipreparasi dimungkinkan memiliki gugus fungsional hidroksida dan karboksilat pada kondisi asam sehingga dapat digunakan untuk mengadsorpsi ion logam $\mathrm{Au}(\mathrm{III})$.

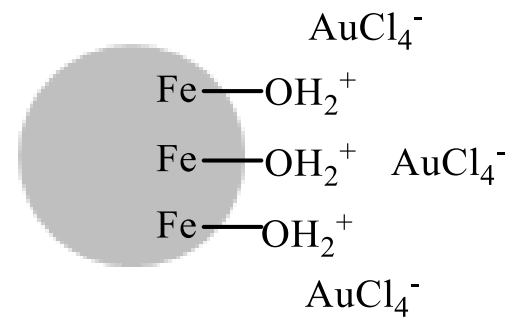

Gambar 4. Prediksi interaksi adsorpsi Au(III) oleh magnetit pasir besi@sitrat

Berdasarkan prediksi tersebut, dapat terlihat bahwa gugus $\mathrm{Fe}-\mathrm{OH}_{2}{ }^{+}$mewakili gugus bermuatan positif, dengan gugus hidroksil dikoordinasikan secara tunggal pada permukaan partikel magnetik dan kompleks $\left[\mathrm{AuCl}_{4}\right]^{-}$dapat diasosiasikan pada permukaan partikel magnetit yang terprotonasi. Interaksi yang terjadi antara partikel magnetit yang bermuatan positif dengan ion logam $\mathrm{Au}(\mathrm{III})$ dalam bentuk $\left[\mathrm{AuCl}_{4}\right]^{-}$yang bermuatan negatif tersebut adalah interaksi elektrostatik.

Hal ini dapat terjadi karena adanya pengaruh nilai titik nol muatan atau point of zero charge (PZC) dari partikel magnetik. PZC dari partikel magnetik berada di kisaran $\mathrm{pH}$ 6,0 sampai 8,2 seperti yang dikemukakan oleh Cornell dan Schwertmann (2003). Pada pH kurang dari PZC, permukaan partikel magnetik akan didominasi oleh gugus $\equiv \mathrm{Fe}_{-}-\mathrm{OH}_{2}{ }^{+}$. Pada $\mathrm{pH}$ lebih dari $\mathrm{PZC}$, permukaan partikel magnetik akan didominasi oleh gugus $\equiv \mathrm{Fe}-\mathrm{O}$. Proses adsorpsi pada penelitian ini berada pada $\mathrm{pH} 3$, maka permukaan partikel magnetik akan terprotonasi dan bermuatan positif membentuk gugus $\equiv \mathrm{Fe}-\mathrm{OH}_{2}{ }^{+}$, sehingga dapat 
memfasilitasi adsorpsi ion logam $\mathrm{Au}(\mathrm{III})$ melalui interaksi elektrostatik seperti yang dikemukakan oleh Lakay (2009).

\section{SIMPULAN}

Berdasarkan data hasil karakterisasi dengan spektofotometer FT-IR, dan TEM menunjukkan bahwa magnetit pasir besi@sitrat berhasil dipreparasi. Natrium sitrat mampu mengontrol dispersi magnetit pasir besi. Magnetit pasir besi@sitrat mampu mengadsorpsi ion logam $\mathrm{Au}(\mathrm{III})$ dalam bentuk $\left[\mathrm{AuCl}_{4}\right]^{-}$sebanyak $42,10 \%$ $(83,667 \pm 0,727 \mathrm{mg} / \mathrm{g})$.

\section{UCAPAN TERIMAKASIH}

Penulis mengucapkan terima kasih kepada Fahmiati atas bantuan bahan penelitian.

\section{DAFTAR PUSTAKA}

Buhani, Suharso, and Sembiring, Z., 2006, Biosorption of Metal Ions $\mathrm{Pb}(\mathrm{II}), \mathrm{Cu}(\mathrm{II})$, and $\mathrm{Cd}(\mathrm{II})$ on Sargassum Duplicatum Immobilized Silica Gel Matrix, Indo. J. Chem., 6, 245-250.

Chung, J., Chun, J., Lee, J., Lee, S.H., Lee, Y.J., and Hong, S.W., 2012, Sorption of $\mathrm{Pb}$ (II) and $\mathrm{Cu}(\mathrm{II})$ Onto Multi-amine Grafted Mesoporous Silica Embedded with NanoMagnetite: Effects of Steric Factors, $J$. Hazard. Mater., 239-240, 183-191.

Cornell, R.M., and Shwertmann, U., 2003, The Iron Oxide: Scructure, Properties, Reaction, Occurences and Uses, Second edition: WILEY-VOH GmbH\&Co. KGaA.

Corti, C.W., Holliday. R.J., and Thompson, D.T, 2007, Progress Towards The Commercial Application of Gold Catalysts, Top. Catal., 44, 331-343.

Farimani, N.S., Roknabadi, N.G., and Kazemi, A., 2013, Study of Structural And Magnetic Properties of Super-paramagnetic $\mathrm{Fe}_{3} \mathrm{O}_{4} / \mathrm{SiO}_{2}$ Core-Shell Nanocomposites Synthe-sized with Hydrophilic Citrate-Modified $\mathrm{Fe}_{3} \mathrm{O}_{4}$ Seeds via A Sol-Gel Approach, Physica E., 53, 207-216.

Gupta, V.K., and Rastogi, A., 2008, Biosorption of Lead from Aqueous Solutions by Green Algae
Spirogyra Species: Kinetics and Equilibrium Studies, J. Hazard. Mater., 152, 407-414.

Hong, R.Y., Li, J.H., Li, H.Z., Ding, J., Zheng, Y., and Wei. D.G., 2008, Synthesis of $\mathrm{Fe}_{3} \mathrm{O}_{4}$ Nanoparticles without Inert Gas Protection Used as Precursors of Magnetic Fuids, J. Magn. Magn. Mater., 320, 1605-1614.

Iida, H., Takayanagi, K., Nakanishi, T., and Osaka, T., 2007, Synthesis of $\mathrm{Fe}_{3} \mathrm{O}_{4}$ Nanoparticles with Various Size and Magnetic Properties by Controlled Hydrolysis, J. Colloid Interface Sci., 314, 274-280.

Jacintho, G.V.M., BroIo, A. G., Corio, P., Suarez, P.A.Z., and Rubim, J.C., 2009, Structural Investigation of $\mathrm{MFe}_{2} \mathrm{O}_{4} \quad(\mathrm{M}=\mathrm{Fe}, \quad \mathrm{Co})$ Magnetic Fluids, J. Phys. Chem. C, 113, 7684-7691.

Jitianu, A., Raileanu, M., Crisan, M., Predoi, D.,. Jitianu, M., Stanciu, L., and Zaharescu, M., 2006, $\mathrm{Fe}_{3} \mathrm{O}_{4}-\mathrm{SiO}_{2}$ Nanocompo-sites Obtained via Alkoxide and Colloidal Route, Journal of Sol-Gel Science and Technology, 40, 317323.

Kazemi, A., Farimani, M.H.R., Shahtahmasebi, N., Roknabadi, M.R., and Ghowsc, N., 2013, Study of Structural and Magnetic Properties of Superparamagnetic $\mathrm{Fe}_{3} \mathrm{O}_{4} / \mathrm{SiO}_{2}$ Core-shell Nanocomposites Synthesized with Hydrophilic Citrate-Modified $\mathrm{Fe}_{3} \mathrm{O}_{4}$ Seeds Via a Sol-Gel Approach, Physica E., 53, 207-216.

Kim, Eun-Y., Kim, Min-seuk., Lee, Jae-chun., and Pandey, B.D., 2011, Selective Recovery of Gold from Waste Mobile Phone PCBs by Hydrometallurgical Process, J. Hazard. Mater., 198, 206-215.

Komatina, M., Heinrich, W., and Gudenau, 2004, The Sticking Problem During Direct Reduction of Fine Iron Ore in The Fluidized Bed, J. Metallurgy., 3, 309.

Kraus, A., Jainae, K., Unob, F., and Sukpirom, N., 2009, Synthesis of MPTS-modified Cobalt Ferrite Nanoparticles and Their Adsorption Properties in Relation to Au(III), J. Colloid Interface Sci., 338, 359-365.

Lakay, E. M., 2009, Superparamagnetic IronOxide Based Nanoparticles for The Separation and Recovery of Precious Metals 
from Solution, Thesis, University of Stellenbosch.

Lu, An-Hui., Salabas, E. L., and Schüth, F., 2007, Magnetic Nanoparticles: Synthesis, Protection, Functionalization, and Application, J. Chem. Int. Ed., 46, 12221244.

Lu, Y., Yin, Y., Mayers, B. T., and Xia, Y., 2002, Modifying the Surface Properties of Superparamagnetic Iron Oxide Nanoparticles through A Sol-Gel Approach, Nano Lett., 2, 183-190.

Montagne, F., Mondain-Monval, O., Pichot, C., Mozzanega, H., and Elaissari, 2002, Preparation and Characterization of Narrow Sized (O/W) Magnetic Emulsion, J. Magn. Magn. Mater., 250, 302-312.

Mukherjee, P., Bhattacharya, R., Bone, N., Lee, Y.K., Patra, C.R., Wang, S., Lu, L., Secreto, C., Banerjee, P.C., Yaszemski, M.J., Kay, N.E., and Mukhopadhyay, D., 2007, Potential Therapeutic Application of Gold Nanoparticles in B-chronic Lymphocytic Leukemia (BCLL): Enhancing Apoptosis, J. Nanobiotechnol., 5, 1-13.

Paclawski, K., and Fitzner, K., 2004, Kinetics of Gold(III) Chloride Complex Reduction Using Sulfur(IV), Metall. Mater. Trans. B., 35B., 1071-1085.

Pan, S., Zhang, Y., Shen, H., and Hu, M., 2012, An Intensive Study on The Magnetic Effect of Mercapto-functionalized Nano-magnetic $\mathrm{Fe}_{3} \mathrm{O}_{4}$ Polymers and Their Adsorption Mechanism for the Removal of $\mathrm{Hg}$ (II) from Aqueous Solution, Chem. Eng. J., 210, 564574.

Petcharoen, K., and Sirivat, A., 2012, Synthesis and Characterization of Magnetite Nanoparticles Via The Chemical CoPrecipitation Method, Mater. Sci. Eng. B., $177,421-427$.

Prasdiantika, R., 2015, Sintesis Hibrida Propildietilentriamin-Silika Terlapis pada Bahan Magnetik Pasir Besi untuk Adsorpsi Au(III), Tesis, Jurusan Kimia FMIPA UGM, Yogyakarta.

Qu, R., Sun, C., Wang, M., Ji, C., Xu, Q., Zhang, Y., Wang, C., Chen, H., and Yin, P., 2009, Adsorption of $\mathrm{Au}(\mathrm{III})$ from Aqueous Solution
Using Cotton Fiber/Chitosan Composite Adsorbents, Hydrometallurgy., 100, 65-71.

Sahoo, P.R., and Venkatesh, A.S., 2015, Constraints of Mineralogical Characterization of Gold Ore: Implication for Genesis, Controls and Evolution of Gold from Kundarkocha Gold Deposit, Eastern India, J. Asian Earth. Sci., 97, 136-149.

Silva-Silva, M.J., Mijangos-Ricardez, O.F., Vázquez-Hipólito, V., Martinez-Vargas, S., and López-Luna, J., 2016, Single and Mixed Adsorption of $\mathrm{Cd}(\mathrm{II})$ and $\mathrm{Cr}(\mathrm{VI})$ onto CitrateCoated Magnetite Nanopar-ticles. Desalination and Water Treatment., 57(9), 4008-4017.

Syukur, M., 2014, Sintesis $\mathrm{Fe}_{3} \mathrm{O}_{4} / \mathrm{SiO}_{2}$ Termodifikasi (N-(2-Aminoetil)-3Aminopropil) untuk Adsorpsi-Desorpsi Anionik $\left[\mathrm{AuCl}_{4}\right]^{-}$, Tesis, Jurusan Kimia UGM, Yogyakarta.

Tsuruta, T., 2004, Biosorption and Recycling of Gold Using Various Microorganisms, J. Gen. Appl. Microbiol., 50, 221-228.

Umali, L.J., Duncan, J.R., and Burgess, J.E., 2006, Performance of Dead Azolla Filiculoides Biomass in Biosorption of $\mathrm{Au}$ from Wastewater, Biotechnology. Lett., 28, 45-49.

Watling K. M., 2007, Spectroelectrochemical Studies of Surface Species in The Gold/Thiosulfate System, Thesis, Griffith Science Environment Engineering and Technology, Griffth University, Australia.

Yamaura, M., Camilo, R. L., Sampaio, L.C., Macedo, M.A., Nakamura, N., and Toma, H.E., 2004, Preparation and Characterization of (3-aminopropyl) triethoxysilane-coated Magnetite Nanoparticles, J. Magn. Magn. Mater., 279, 210-217.

Yang, D., Hu. J., and Fu. S., 2009, Controlled Synthesis of Magnetite-Silica Nanocomposites via a Seeded Sol-Gel Approach, $J$. Phys. Chem, 113, 7646-7651.

Yantasee, W., Warner, C.L., Sangvanich, T., Addleman, R.S., Carter, T.G., Wiacek, R.J., Fryxell, G.E., Timchalk, C., and Warner. M.G., 2007, Removal of Heavy Metals from Aqueous Systems with Thiol Functiona-lized Superparamagnetic Nanoparticles, Environ- 
mental Science and Technology., 41(14): 5114-5119.

Zhang, J., Zhai, S., Li, S., Xiao, Z., Song, Y., An, Q., and Tian, G., 2013, Pb(II) Removal of $\mathrm{Fe}_{3} \mathrm{O}_{4} @ \mathrm{SiO}_{2}-\mathrm{NH}_{2}$ Core-shell Nanomaterials Prepared Via a Controllable Sol-gel Process, Chem. Eng. J., 215-216, 461-471.

Zhang, Y., Xu, Q., Zhang, S., Liu, J., Zhou, J., Xu, H., Xiao, H., and Li, J., 2013, Preparation of Thiol-modified $\mathrm{Fe}_{3} \mathrm{O}_{4} @ \mathrm{SiO}_{2}$ Nanoparticles and Their Application for Gold Recovery from Dilute Solution, Sep. Purif. Technol., 116, 391-397. 